\title{
Availability of evidence of benefits on overall survival and quality of life of cancer drugs approved by European Medicines Agency: retrospective cohort study of drug approvals 2009-13
}

\author{
Courtney Davis, ${ }^{1}$ Huseyin Naci, ${ }^{2}$ Evrim Gurpinar, ${ }^{2}$ Elita Poplavska, ${ }^{3}$ Ashlyn Pinto, ${ }^{2}$ \\ Ajay Aggarwal ${ }^{4,5}$
}

${ }^{1}$ Department of Global Health and Social Medicine, King's College London, London WC2R 2LS, UK

${ }^{2}$ LSE Health, Department of Health Policy, London School of Economics and Political Science, London, UK

${ }^{3}$ Faculty of Pharmacy, Riga Stradins University, Riga, Latvia ${ }^{4}$ Department of Health Services Research and Policy, London School of Hygiene and Tropical Medicine, London, UK

${ }^{5}$ Institute of Cancer Policy, King's College London, London, UK

Correspondence to: C Davis courtney.davis@kcl.ac.uk

Additional material is published online only. To view please visit the journal online.

Cite this as: $B M J$ 2017;359:j4530 http://dx.doi.org/10.1136/bmj.j4530

Accepted: 28 September 2017

\section{ABSTRACT}

OBJECTIVE

To determine the availability of data on overall survival and quality of life benefits of cancer drugs approved in Europe.

Design

Retrospective cohort study.

Setting

Publicly accessible regulatory and scientific reports on cancer approvals by the European Medicines Agency (EMA) from 2009 to 2013.

Main outcome measures

Pivotal and postmarketing trials of cancer drugs according to their design features (randomisation, crossover, blinding), comparators, and endpoints. Availability and magnitude of benefit on overall survival or quality of life determined at time of approval and after market entry. Validated European Society for Medical Oncology Magnitude of Clinical Benefit Scale (ESMO-MCBS) used to assess the clinical value of the reported gains in published studies of cancer drugs.

Results

From 2009 to 2013, the EMA approved the use of 48 cancer drugs for 68 indications. Of these, eight indications (12\%) were approved on the basis of a single arm study. At the time of market approval, there was significant prolongation of survival in 24 of the 68 (35\%). The magnitude of the benefit on overall survival ranged from 1.0 to 5.8 months (median 2.7 months). At the time of market approval,

\section{WHAT IS ALREADY KNOWN ON THIS TOPIC}

Clinical trials designed to gain regulatory approval for new drugs often evaluate surrogate measures that do not always reliably predict clinically meaningful outcomes like survival or quality of life

Recent reviews from the US show that only a small proportion of cancer drugs approved by the US Food and Drug Administration improve survival or quality of life

No recent studies have systematically examined the evidence base for and magnitude of benefit for cancer drugs approved by the EMA

\section{WHAT THIS STUDY ADDS}

Most new oncology drugs authorised by the EMA in 2009-13 came onto the market without clear evidence that they improved the quality or quantity of patients' lives

After market entry, cancer drugs rarely show benefits on overall survival or quality of life in randomised trials

When survival gains over available treatment alternatives are shown, they are not always clinically meaningful there was an improvement in quality of life in seven of 68 indications (10\%). Out of 44 indications for which there was no evidence of a survival gain at the time of market authorisation, in the subsequent postmarketing period there was evidence for extension of life in three (7\%) and reported benefit on quality of life in five (11\%). Of the 68 cancer indications with EMA approval, and with a median of 5.4 years' follow-up (minimum 3.3 years, maximum 8.1 years), only 35 (51\%) had shown a significant improvement in survival or quality of life, while $33(49 \%)$ remained uncertain. Of 23 indications associated with a survival benefit that could be scored with the ESMO-MCBS tool, the benefit was judged to be clinically meaningful in less than half $(11 / 23$, $48 \%)$.

Conclusions

This systematic evaluation of oncology approvals by the EMA in 2009-13 shows that most drugs entered the market without evidence of benefit on survival or quality of life. At a minimum of 3.3 years after market entry, there was still no conclusive evidence that these drugs either extended or improved life for most cancer indications. When there were survival gains over existing treatment options or placebo, they were often marginal.

\section{Introduction}

Before new prescription medicines are allowed onto the market, they must be tested in studies and show, to the satisfaction of drug regulatory agencies, that their benefits outweigh the harms of drug toxicity. The most informative and valuable studies are those providing robust evidence from well designed randomised controlled trials that a new drug has a significant effect on outcomes that are important to patients and that the magnitude of those effects, compared with other treatment options, are clinically meaningful. Although the goal of cancer treatment is to improve the quantity and quality of life, ${ }^{123}$ clinical trials designed to gain regulatory approval for new drugs often evaluate indirect or "surrogate" measures of drug efficacy. These endpoints show that an agent has biological activity, but they are not reliable surrogates for improved survival $^{\text {4-11 }}$ or quality of life $\mathrm{e}^{4611-13}$ in all settings, and two recent systematic reviews suggest that the strength of association between surrogates in cancer clinical trials and life extension is generally low. ${ }^{814}$ Moreover, there is growing concern that the benefits offered by many new treatments for cancer-often discussed and promoted as "breakthroughs"15-18_are marginal and might not be clinically meaningful to patients, despite 
rapidly escalating costs. ${ }^{19-23}$ Consequently, there have been calls to raise the evidence bar for market authorisation of new cancer drugs. ${ }^{15} 21$ 23-26

No recent studies have systematically examined the evidence base and magnitude of benefit for cancer drugs approved by the European Medicines Agency (EMA). ${ }^{27-29}$ Available data from the US show that only a small proportion of cancer treatments approved by the US Food and Drug Administration (FDA) unequivocally show benefits on survival or quality of life. ${ }^{30}$ The applicability of this evidence to the European context, however, is not clear. Recent FDA-EMA comparisons show differences in regulatory decisions, route of approval, and availability of cancer drugs that could have important implications for clinical practice and patient safety. ${ }^{31-35}$ In particular, regulatory provisions for expediting drug development and approval differ between the US and the EU, ${ }^{32}$ with EU regulation being more restrictive in scope. ${ }^{36}$ This could lead to divergent outcomes between the two regions.

The proportion of cancer drugs approved by the EMA without any demonstrable benefits on survival or quality of life is not known. In addition, whether treatments approved without evidence of benefit on survival are subsequently shown to improve survival or quality of life in postmarketing studies has not been characterised.

We sought to systematically evaluate the evidence base for all new drugs and new indications for the treatment of solid tumours and haematological malignancies approved by the EMA in the five year period 2009-13. We determined the proportion of drugs with demonstrable benefit on survival or quality of life over available treatment options or placebo, both at time of approval and in the postmarketing period. In addition, we used a validated scale to evaluate the magnitude of benefit of drugs in our sample showing a significant improvement on survival in the treatment of solid cancers.

\section{Methods}

\section{Cohort of cancer drugs approved by EMA 2009-13}

We searched the publicly available EMA database of European Public Assessment Reports using L01-04 ATC codes to identify "antineoplastic and immunomodulating” agents for solid tumours and haematological malignancies authorised from 1 January 2009 to 31 December 2013. Consistent with previous research, ${ }^{30}$ our study period ended in 2013, which allowed adequate time for the completion of randomised trials in the postmarketing period. We excluded paediatric indications, indications for the treatment of benign tumours, supportive treatments, and generic products (fig A in appendix). Authorised indications for each drug were identified by searching the EPAR document "Procedural steps taken and scientific information after authorisation."

We distinguished between different types of regulatory approval. A "first marketing authorisation" indicates that the drug is a new active substance, approved onto the EU market for the first time. An "extension" to a marketing authorisation is when a marketed drug is approved for use in a new patient population, new combination, new line of treatment, or new type of cancer. By law, a "regular marketing authorisation" should be based on comprehensive evidence of quality, safety, and efficacy. "Conditional marketing authorisations" can be granted for drugs intended to treat patients with seriously debilitating or life threatening diseases and are expected to fulfil an unmet medical need. Conditional approvals are granted on the basis of less comprehensive data than required for a regular marketing authorisation, and companies are required to generate additional evidence in the postmarketing period. ${ }^{36}$ "Orphan drug" designation is granted for the treatment of rare cancers. We also categorised indications according to cancer site and stage of disease (specifically whether treatments were to be used in a curative or non-curative setting).

\section{Data sources and search strategies}

To determine the availability of evidence on overall survival and quality of life gains at time of market approval for the drugs in our cohort, we manually searched the EMA website to identify the relevant European Public Assessment Reports (EPARs). EPARs are official regulatory documents in the public domain that summarise the evidence base for a new drug or new indication and provide a justification for the EMA's decision to grant a marketing authorisation or extension to the marketing authorisation. Clinical trial data supporting approval of each of the unique indications were retrieved from the EPARs. We included only data from those studies identified by the EMA as the main, or "pivotal," studies supporting approval.

To determine whether drugs that did not show any survival gain at the time of approval were subsequently confirmed to improve survival or quality of life in the postmarketing period, we searched PubMed for randomised controlled trials reporting these outcomes for the relevant indications. Our search strategy included the drug name, approved indication, and search terms for the endpoints of interest (overall survival or quality of life or QoL or HRQoL) (fig B in appendix). We identified randomised controlled trials using the Cochrane Collaboration sensitivity and precision maximising search strategy for identifying randomised trials. ${ }^{37}$ When possible, we cross checked search results against the European Clinical Trials Database (EudraCT) and the US National Library of Medicine database of clinical trials (ClinicalTrials. gov). Our latest search was on 31 March 2017, which allowed for at least 3.3 years for the completion and publication of clinical studies in the postmarketing period (median 5.4 years, maximum 8.1 years).

For those drugs associated with an overall survival gain at the time of approval or in the postmarketing period, we used the European Society for Medical Oncology's (ESMO) Magnitude of Clinical Benefit Scale (ESMO-MCBS) to assess the clinical value of these gains as reported in published studies. ${ }^{38}$ The ESMO-MCBS scale is a tool for evaluating the 
clinical benefit of new treatments for solid tumours to facilitate the presentation of clear and unbiased statements regarding the relative clinical benefit of new treatments.

\section{Data extraction, outcome variables, and data} analysis

Three investigators (AP, EP, and EG) independently extracted data on and descriptively analysed the following trial features: characteristics of the participant population, study design (randomisation, crossover from experimental to control group, and blinding of investigators and participants), experimental and control groups, enrolment, primary and secondary endpoints, magnitude of benefit on survival and quality of life, and narrative interpretation of the findings. We classified comparators as active (in trials comparing drugs A versus B), add on (in trials comparing drugs $A+B$ versus $B$ alone), placebo, or none. Investigators cross checked each other's data extraction. Difficulties or disagreements in interpretation were resolved by discussion and consensus among the three lead investigators (CD, HN, and AA). All data were also checked by the principal investigator (CD).

We judged that a drug had shown a survival benefit in its approved indication if, as reported in the EPAR or study publication, overall survival was the primary or secondary endpoint in a randomised controlled trial, and the difference in survival between the experimental and control arms was significant according to a prespecified statistical analysis. If an analysis was described as "exploratory" we considered it to be a post hoc analysis. Post hoc analyses (in which the hypotheses being tested were not specified before examination of the data) were accepted if the EMA specifically determined that these analyses provided evidence of a survival benefit. If a published study reporting results of a pivotal trial conflicted with the EMA's assessment or other information contained in an EPAR, we made a determination consistent with the EPAR, unless the published study reported an updated analysis.

We considered that a drug had shown a benefit on quality of life in its approved indication when a significant difference was reported for an item or subscale derived from a validated quality of life instrument, even in the absence of a significant benefit with respect to the global score.

\section{Determination of ESMO-MCBS score}

Our scoring was limited to drugs for solid tumours as the ESMO scales are not intended for evaluation of drugs to treat haematological malignancies. ${ }^{38}$ Two investigators (AA and CD) independently graded individual trials based on published papers that reported a significant difference in overall survival (as a prespecified primary or secondary study endpoint) using the most recent version of the ESMO-MCBS evaluation forms. ${ }^{39}$ There was complete agreement between the two investigators in the scoring. As per the established ESMO methods, each score was assigned based on the magnitude of the absolute survival gain and the lower limit of the $95 \%$ confidence interval of the hazard ratio, and only significant changes in toxicity or quality of life parameters were used to modify the grades. Only scores of A or B (for treatments of curative intent), or 5 or 4 (for treatments used in the non-curative/palliative setting) are defined as clinically meaningful according to the ESMO framework.

\section{Patient involvement}

No patients were involved in setting the research question or the outcome measures, nor were they involved in developing plans for design or implementation of the study. No patients were asked to advise on interpretation or writing up of results. There are no plans to disseminate the results of the research to study participants or the relevant patient community.

\section{Results}

From 2009 to 2013, the EMA approved use of 48 oncology drugs in 68 indications. Of the authorised indications for use, 33 were first marketing authorisations and 35 were extensions (see methods for definitions) Table 1and table A in the appendix show the approved indication and the date and type of market authorisation for each agent. Some 58 uses were granted a regular marketing authorisation, of which seven were designated as orphan drugs. Ten uses were granted conditional marketing authorisation (including four designated as orphan drugs). In total, $11 / 68(16 \%)$ uses received orphan designation. Approval for one (bevacizumab in combination with docetaxel for the treatment of metastatic breast cancer) was subsequently withdrawn. ${ }^{40}$

Seventeen drugs were approved for treatment of haematological malignancies and 51 for treatment of solid tumours. Of these 51, 12 (24\%) were for breast cancer, seven (14\%) for lung cancer, five for bowel cancer, and five $(10 \%)$ for prostate cancer. Of the 17 drugs approved for treatment of haematological malignancies, four (24\%) were for chronic myeloid leukaemia, three (18\%) for multiple myeloma, and three (18\%) for chronic lymphocytic leukaemia. Most drugs $(61 / 68,90 \%)$ were approved for use in a noncurative setting (table 1).

\section{Characteristics of pivotal studies}

Overall, 72 clinical trials supported the approval of 68 novel drug uses. Only 18 of the 68 (26\%) were supported by a pivotal study powered to evaluate overall survival as the primary outcome (table 2 and table B in appendix). Survival was evaluated as the primary study endpoint in none of the 10 conditionally authorised uses and in only one of the $11(9 \%)$ with an orphan designation. Overall survival was evaluated as a primary study endpoint in less than a third (18/58, $31 \%$ ) of all drug indications granted regular marketing authorisation. 


\begin{tabular}{|c|c|c|}
\hline Characteristics & Solid tumours $(n=51)$ & $\begin{array}{l}\text { Haematologica } \\
\text { tumours }(n=17)\end{array}$ \\
\hline \multicolumn{3}{|l|}{ Type of marketing authorisation: } \\
\hline First marketing authorisation & $24(47)$ & $9(53)$ \\
\hline Extension & $27(53)$ & $8(47)$ \\
\hline \multicolumn{3}{|c|}{ Pathway of first marketing authorisation: } \\
\hline Regular approval & $19(79)$ & $4(44)$ \\
\hline Conditional approval & $5(21)$ & $5(56)$ \\
\hline Orphan designation & $3(6)$ & $8(47)$ \\
\hline \multicolumn{3}{|l|}{ Intent of treatment: } \\
\hline Curative & $6(12)$ & $1(6)$ \\
\hline Non-curative & $45(88)$ & $16(94)$ \\
\hline
\end{tabular}

The remaining drug indications were supported by trials that evaluated a surrogate measure as the primary study outcome (table 2 and table B in appendix). This included progression-free survival for 31 (46\%); response rate (including cytogenetic, haematological, and molecular response rates for haematological indications) for 11 (16\%); disease-free survival for four (6\%); with time to progression, event-free survival, relapse-free survival, and testosterone concentrations accounting for the remainder $(4 / 68,6 \%)$.

Just over half $(37 / 68,54 \%)$ of all drug indications had a supporting pivotal trial evaluating quality of life, but results were reported for only 35. None of the pivotal trials assessed quality of life as a primary endpoint (table 2).

Of 68 drug indications, $60(88 \%)$ were supported by at least one randomised controlled trial, while eight of $68(12 \%)$ were approved solely on the basis of a single arm study (6/10 indications granted a conditional marketing authorisation and 2/58 granted a regular marketing authorisation) (table 2 and table $\mathrm{B}$ in appendix). Most $(6 / 8,75 \%)$ authorised uses supported by uncontrolled studies were also orphan designations. On the other hand, more than half of the orphan drugs in our cohort $(7 / 11,64 \%)$ were approved on the basis of a randomised trial.

Availability of evidence on overall survival and quality of life at time of market authorisation At time of market approval, according to the EPARs, there was significant prolongation of survival in just

\begin{tabular}{|c|c|c|}
\hline Characteristics & Solid tumours $(n=54)$ & $\begin{array}{l}\text { Haematological } \\
\text { tumours }(n=18)\end{array}$ \\
\hline \multicolumn{3}{|l|}{ Pivotal trial design: } \\
\hline Randomised trial & $52(96)$ & $13(72)$ \\
\hline Single arm trial & $2(4)$ & $5(28)$ \\
\hline \multicolumn{3}{|l|}{ Comparator: } \\
\hline Active & $15(28)$ & $9(50)$ \\
\hline Placebo & $25(46)$ & $0(0)$ \\
\hline Add on & $12(22)$ & $4(22)$ \\
\hline None & $2(4)$ & $5(28)$ \\
\hline OS as primary endpoint & $18(33)$ & $1(6)$ \\
\hline OS or QoL as secondary endpoint & $47(87)$ & $17(94)$ \\
\hline Median (range) sample size & $696(96-3222)$ & $484(58-1018)$ \\
\hline
\end{tabular}

over a third $(24 / 68,35 \%)$ of all drug indications (including $3 / 17$ drugs to treat haematological malignancies and 21/51 drugs to treat solid tumours). There were gains in survival for seven compared with an active comparator, eight compared with placebo, one compared with best supportive care, and eight as add on treatment. The magnitude of the overall survival benefit ranged from 1.0 to 5.8 months (median 2.7 months) (fig 1). For the 44 (65\%) remaining drug indications, there was no conclusive evidence at time of market authorisation that the drugs offered survival benefits, either as add on treatment or compared with placebo or existing treatment options in their authorised use.

\section{Availability of evidence on overall survival and} quality of life in postmarketing period

Of the 44 drug indications that did not show a survival benefit at time of approval, and with a median of 5.4 years' follow-up (minimum of 3.3 years and maximum of 8.1 years), three (7\%) were subsequently shown to extend life after market entry and five (11\%) were associated with some improvements in quality of life (fig 2).

For all three drug indications with a reported survival gain in the postmarketing period, evidence came from updated analyses of the pivotal studies supporting initial marketing authorisation, and all had been granted regular marketing approval. None of the 10 drugs granted conditional marketing authorisation were subsequently shown to improve quantity or quality of life. One of 68 authorised uses judged by the EMA to extend life at time of market authorisation failed to show such a benefit on longer follow-up according to the published report. ${ }^{41}$ Thus, with a minimum 3.3 years' follow-up, in 26 of the 68 (38\%) authorised drug indications there was a survival gain (including three of the seven drugs approved for use in a curative setting).

For the five drug indications with a reported improvement in quality of life, evidence came from new studies in the same indicated population with the exception of nilotinib, for which a published paper ${ }^{42}$ reporting the pivotal study described quality of life gains not reported in the EPAR. Box 2 lists those drugs not shown to extend life, but which were associated with a quality of life benefit with a median of 5.4 years' follow-up.

\section{Proportion of EMA oncology approvals meeting ESMO threshold for clinically meaningful survival benefit}

Table 3 shows the ESMO-MCBS scores for all the drugs to treat solid tumours that showed benefit on overall survival by the time of our study cut off. After a median of 5.4 years' follow-up 26 drug indications were associated with a survival gain, but three of these were for haematological cancers, leaving a total of 23 to which the ESMO scale could be applied.

Of these 23 drugs, 11 (48\%) reached the ESMO threshold for a meaningful survival benefit; eight out 
Fig 1 | Magnitude of overall survival benefit at the time of EMA approval. Figure excludes seven indications for which median overall survival could not be estimated at time of marketing authorisation: mifamurtide for resectable nonmetastatic osteosarcoma after complete resection (+chemo); pertuzumab for 1st line HER2+mBC; pomalidomide for 3 rd line (+dexamethasone) relapsed and refractory multiple myeloma; rituximab for 1 st line CLL (+chemo); trastuzumab for HER2+ BC (+taxane) after adjuvant chemo; trastuzumab for HER2+BC (+adjuvant chemo); and trastuzumab for HER2+locally advanced BC (+neoadjuvant chemo and as monotherapy adjuvantly). Box 1 shows abbreviations used
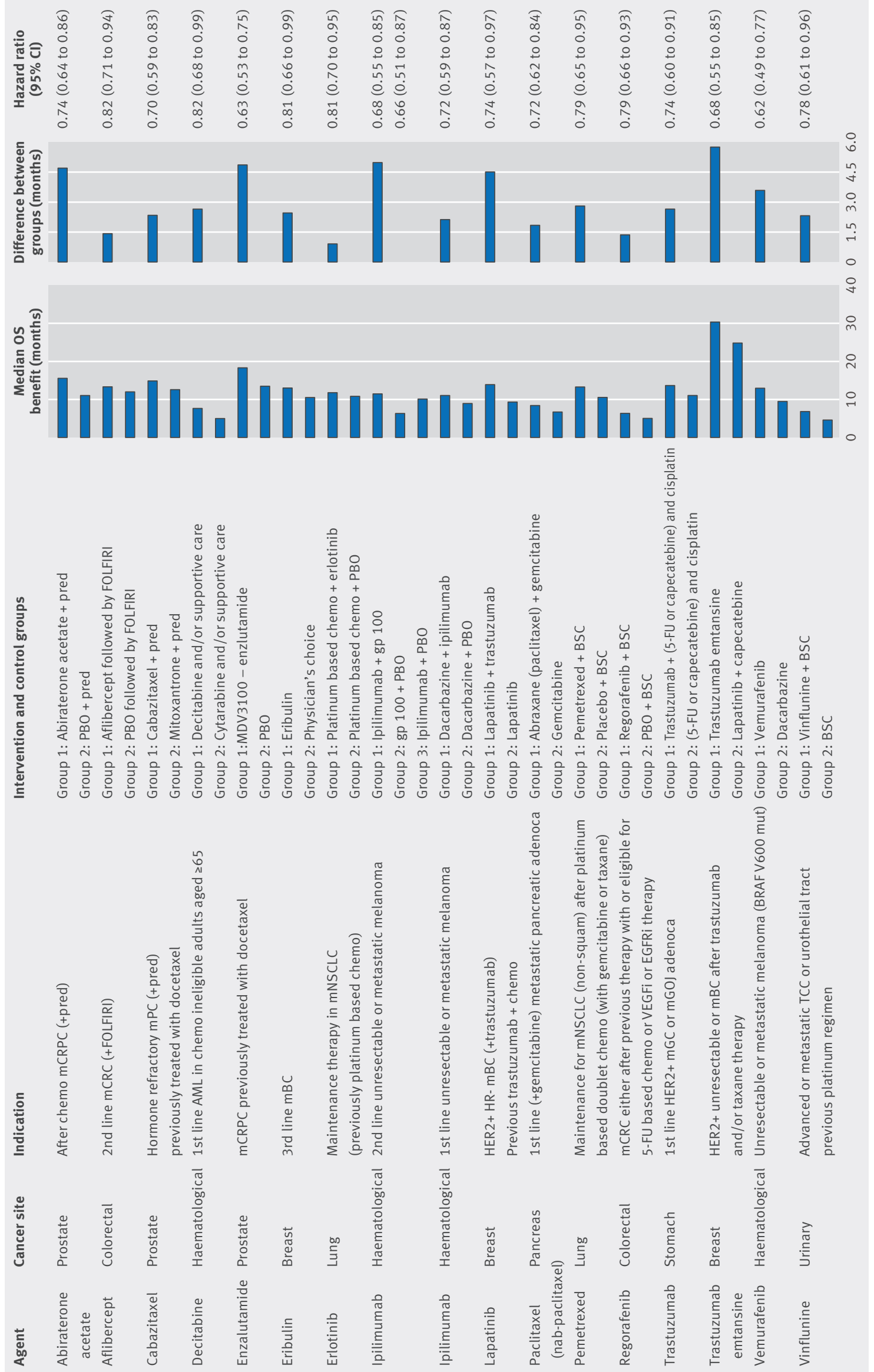


\section{Box 1: Abbreviations used in tables and figures}

$5 F U=5$ fluorouracil; adenoca=adenocarcinoma; $\mathrm{Al}=$ aromatase inhibitor; $\mathrm{ALCL}=$ anaplastic large cell lymphoma; $\mathrm{ALK}=$ anaplastic lymphoma kinase; $A L L=$ acute lymphoblastic leukaemia; $A M L=$ acute myeloid leukaemia; $A P=$ accelerated phase; $A S C T=$ autologous stem cell transplant; $B C=b r e a s t$ cancer; $\mathrm{BCC}=$ basal cell carcinoma; $\mathrm{BP}=$ blast phase; chemo: $\mathrm{BCS}=$ best supportive care; chemo=chemotherapy; $C L L=$ chronic lymphocytic leukaemia; $\mathrm{CML}=$ chronic myelogenous leukaemia; $\mathrm{CP}=$ chronic phase; $\mathrm{EFGR=epidermal} \mathrm{growth} \mathrm{factor} \mathrm{receptor;} \mathrm{EGFRi=epidermal} \mathrm{growth} \mathrm{factor}$ receptor inhibitor; FOLFIRI: irinotecan/5 fluorouracil/folinic acid; FOLFOX: oxaliplatin/5 fluorouracil/folinic acid; GC=gastric cancer; $\mathrm{GIST}=$ gastrointestinal stromal tumours; $\mathrm{HL}=$ Hodgkin lymphoma; $\mathrm{HR}=$ hormone receptor; $\mathrm{mBC}=$ metastatic breast cancer; $\mathrm{MCL}=$ mantle cell lymphoma; $\mathrm{mCRC}=$ metastatic colorectal cancer; $\mathrm{mCRPC}=$ metastatic castration resistant prostate cancer; $\mathrm{mGC}=$ metastatic gastric cancer; $\mathrm{mGOJ}=$ metastatic gastric or esophageal junction; $\mathrm{mNSCLC}=$ metastatic non-small cell lung cancer; $\mathrm{mPC}=$ metastatic prostate cancer; mut=mutation; non-squam=non-squamous; $\mathrm{PBO}=$ placebo; $\mathrm{NHL}=$ non-Hodgkin lymphoma; $\mathrm{NR}=$ not reported; $\mathrm{PC}=$ prostate cancer; $\mathrm{Ph}+=$ Philadelphia chromosome positive; $\mathrm{PLD}=$ pegylated liposomal doxorubicin; $\mathrm{PNET}=$ pancreatic neuroendocrine tumours; pred=prednisone or prednisolone; $\mathrm{RCC}=$ renal cell carcinoma; $\mathrm{SCT}=$ stem cell transplantation; squam=squamous; $\mathrm{STS}=$ soft tissue sarcoma; $\mathrm{TC}=$ thyroid cancer; TCC=transitional cell carcinoma; TKI=tyrosine kinase inhibitor; VEGFi=vascular endothelial growth factor inhibitor; WT=wild-type

There was a significant improvement in quality of life over the control arm in only seven of the 68 (10\%) authorised drug indications. Five of these were drug indications for which there was no survival gain at the time of market authorisation, giving a total of 29 of 68 ( $43 \%$ ) that did show improvements in either quantity or quality of life at time of market entry.

The remaining 39 (57\%) drugs had shown no improvement in survival or quality of life over active treatment, placebo, or as add on treatment. Eleven were evaluated against an active comparator, and 10 of these had comparable efficacy with respect to survival, although in most cases survival data were immature. Twenty were evaluated against placebo or as add on treatment and showed no gains in survival or quality of life. Eight were approved on the basis of a single arm trial.

\begin{tabular}{|c|c|}
\hline Agent & Indication \\
\hline Degarelix & Advanced PC \\
\hline $\begin{array}{l}\text { Rituximab } \\
\text { Mifamurtide }\end{array}$ & $\begin{array}{l}\text { 1st line CLL (+chemo) } \\
\text { Resectable non-metastatic osteosarcoma after complete resection (+chemo) }\end{array}$ \\
\hline Imatinib & Adjuvant treatment for high risk GIST \\
\hline Gefitinib & EGFR mut+mNSCLC \\
\hline Pemetrexed & Maintenance for mNSCLC (non-squam) after platinum based doublet chemo (w/gemcitabine or taxane) \\
\hline $\begin{array}{l}\text { Bevacizumab } \\
\text { Everolimus }\end{array}$ & $\begin{array}{l}\text { 1st line } \mathrm{mBC}(+ \text { docetaxel) } \\
\text { Advanced RCC after VEGF targeted treatment }\end{array}$ \\
\hline Rituximab & $\begin{array}{l}\text { Advanced RCC after VEGF targeted treatment } \\
\text { Relapsed/refractory CLL (+chemo) }\end{array}$ \\
\hline nflunine & Advanced or metastatic TCC of urethral tract. Previous platinum regimen \\
\hline Temsirolimus & Relapsed or refractory $\mathrm{MCL}$ \\
\hline abectedin & Relapsed (platinum sensitive) ovarian cancer (+PLD) \\
\hline nab & line $\mathrm{HER} 2+\mathrm{mGC}$ or $\mathrm{mGOJ}$ adenoCa \\
\hline Ofatumumab & $\mathrm{CLL}$ refractory to fludarabine and alemtuzumab \\
\hline tin & nemo) \\
\hline patinib & (+aromatase inhibitor). No $p$ \\
\hline zopanib & 1st line advanced RCC \\
\hline Pazopanib & 2nd line advance RCC (previous cytokine) \\
\hline Docetaxel & bicin and cy \\
\hline$a b$ & M \\
\hline Sunitinib & 2nd line unresectable or metastatic well diff \\
\hline Dasatinib & 1 st line $\mathrm{Ph}+\mathrm{CML}(\mathrm{CP})$ \\
\hline Nilotinib & adult Ph+CML (CP) \\
\hline Tegafur/gimerac & Advanced GC (+cisplatin) \\
\hline Cabazitaxel & Hormone refractory mPC (+pred) previously treated with docetaxel \\
\hline $\begin{array}{l}\text { ibulin } \\
\text { astuzumab }\end{array}$ & C \\
\hline $\begin{array}{l}\text { Trastuzumab } \\
\text { Trastuzumab }\end{array}$ & $\begin{array}{l}\text { HER2+BC (+taxane) after adjuvant chemo } \\
\text { HER2+BC (+ adjuvant chemo) }\end{array}$ \\
\hline Bevacizumab & 1 st line $\mathrm{mBC}$ (+capecitabine). No previous taxanes or anthracyclines \\
\hline & $2 n$ \\
\hline se & 1st lin \\
\hline erolimus & Unresectable or metastatic well or moderately differentiated PNET \\
\hline iraterone acetate & mCRPC ( \\
\hline & Maintenanc \\
\hline & 1st lin \\
\hline Imab & RC (+FOLFIRI) \\
\hline nab & litaxel) in stage \\
\hline & \\
\hline 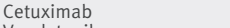 & $1 \mathrm{~s}$ \\
\hline ib & Un \\
\hline & AFVE \\
\hline & \\
\hline olimus & gative BC (+exemetane) \\
\hline nib & nemo or progressed within 12 months after neo-adjuvant therapy) \\
\hline & \\
\hline abine & 1st line AML in adults aged $\geq 65$ ineligible for chemo \\
\hline & dvanced NSCLC \\
\hline $\begin{array}{l}\text { Bevacizumab } \\
\text { Brentuximab vedotin }\end{array}$ & $\begin{array}{l}\text { 2nd line (+carboplatin and gemcitabine) platinum sensitive ovarian, fallopian, or primary peritoneal cancer. No previous VEGF } \\
\text { Relapsed or refractory CD } 30+\mathrm{HL} \text { after ASCT or } 3 \text { rd line if ineligible for ASCT }\end{array}$ \\
\hline Brentuximab vedotin & Relapsed or refractory systemic ALCL \\
\hline $\begin{array}{l}\text { Abiraterone acetate } \\
\text { Aflibercept }\end{array}$ & $\begin{array}{l}\text { mCRPC (+pred) before chemo } \\
\text { 2nd line mCRC (+FOLFIRI) }\end{array}$ \\
\hline & ine HER2 + $m B C$ \\
\hline & or 3 rd line CP, AP, BP, Ph \\
\hline & xel \\
\hline & ineligible for imatinib \\
\hline & I \\
\hline & \\
\hline & HER2+HR- mBC (+trastuzumab). Previous tra \\
\hline & hasone+thalidomide) \\
\hline lomide & \\
\hline enib & Unresectable or metastatic melanoma w/BRAF V600 mut \\
\hline & $\mathrm{mCRC}$ either after previous treatment with/ or ineligible for $5 F U$ based chemo or VEGFi or EGFRi treatment \\
\hline - & \\
\hline ansine & $\begin{array}{l}\text { 1st line unresectable or metastatic } \\
\text { HER2+ unresectable or } m B C \text { after } t\end{array}$ \\
\hline $\begin{array}{l}\text { Tras } \\
\mathrm{Nab}\end{array}$ & unresectable or $\mathrm{mBC}$ after $\mathrm{t}$ \\
\hline Bortezomib & 2nd line multiple myeloma ineligible for SCT (monotherapy or +doxorubicin or dexamethasone) \\
\hline
\end{tabular}

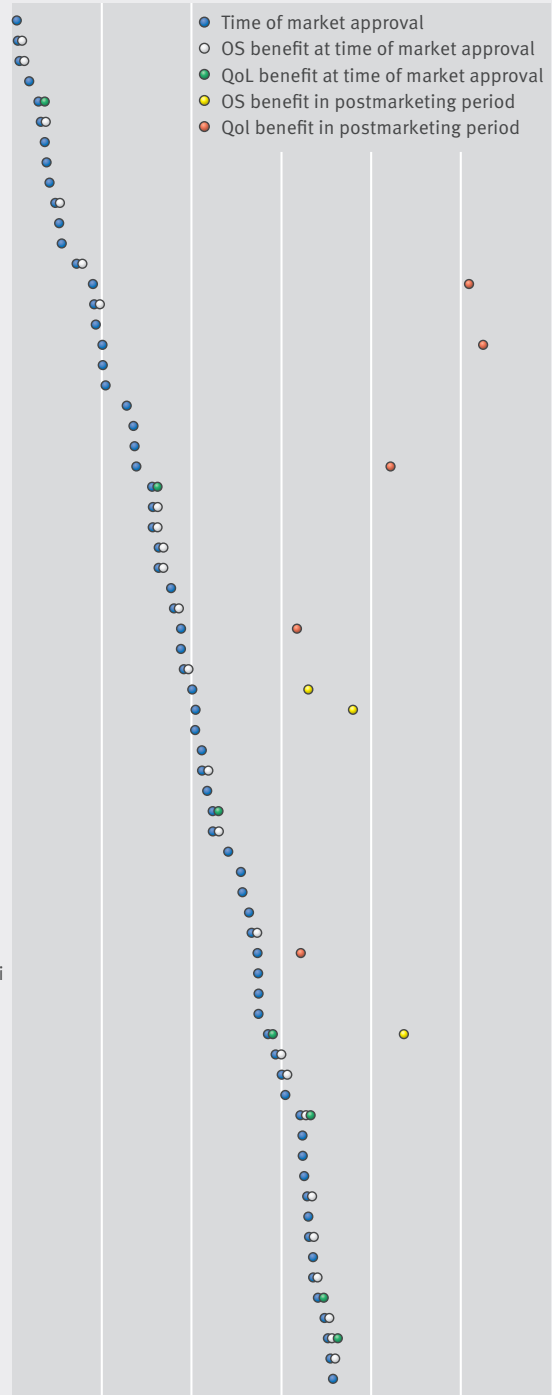

01/2009 06/2010 10/2011 $02 / 2013 \quad 07 / 2014 \quad 11 / 2015 \quad 04 / 2017$

Fig 2 | Availability of benefits on overall survival and quality of life of cancer drugs approved 2009-13. Box 1 shows abbreviations used 


\section{Box 2: Cancer drugs associated with benefit on health related quality of life (HRQoL)}

\section{Reported at time of market approval}

- Afatinib $v$ pemetrexed/cisplatin (for the treatment of TKI-naive, EGFR mutation +ve, non-small cell lung cancer) significantly delayed the time to deterioration for cough and dyspnoea but not time to deterioration of pain. HRQoL was evaluated against prespecified components of the European Organisation for Research and Treatment of Cancer quality of life questionnaire C30 (EORTC QLQ-C30) questionnaire and lung cancer module QLQ-LC13. The study was open label ${ }^{43}$

- Gefitnib (for the treatment of metastatic non-small cell lung cancer) showed significant benefits on quality of life compared with carboplatin plus paclitaxel, and with docetaxel on some measures, but not compared with placebo. HRQoL was assessed with the functional assessment of cancer therapy-lung (FACT-L), and trial outcome index (TOI), and symptom improvement by the lung cancer subscale (LCS). The active comparator trials were open label. The trial $v$ placebo was double blind ${ }^{44}$

- Tegafur, gimeracil, oteracil (S-1) (in combination with cisplatin for the treatment of advanced gastric cancer) showed a significant improvement over cisplatin/5-fluorouracil for only one of the subscales (physical wellbeing) of the functional assessment of cancer therapy-gastric (FACT-Ga) HRQOL instrument. The study was open label ${ }^{45}$

- Vandetanib $v$ placebo (for the treatment of metastatic medullary thyroid cancer) significantly improved "time to worsening of pain" (a composite endpoint based on patient reported analgesic use and responses to the brief pain inventory) but did not show a significant improvement for the functional assessment of cancer therapy-general (FACT-G) score. The study was double blind ${ }^{46}$

\section{Reported in the postmarketing period}

- Crizotinib (for second line treatment of ALK mutation +ve advanced non-small cell lung cancer) showed significant improvements compared with pemetrexed across a range of HRQoL measures, including a significantly greater delay in time to worsening of symptoms. HRQoL was assessed with the European Organisation for Research and Treatment of Cancer quality of life questionnaire C30 (EORTC QLQ-C30) and the lung cancer module QLQ-LC13. The study was open label ${ }^{47}$

- Erlotinib (for first line treatment of EGFR mutation +ve metastatic non-small cell lung cancer) showed clinically relevant and significant improvements compared with gemcitabine/carboplatin in total functional assessment of cancer therapy-lung (FACT-L), trial outcome index (TOI), and lung cancer subscale (LCS) scores. The study was open label ${ }^{48}$

- Nilotinib $v$ imatinib (for patients with newly diagnosed $\mathrm{Ph}+$ chronic myeloid leukaemia) reported a significant quality of life improvement with respect to some categories of low grade adverse events. HRQoL was assessed with generic SF-36 and leukaemia specific functional assessment of cancer therapy-leukaemia (FACT-Leu) surveys. The study was open label ${ }^{42}$

- Ofatumumab (in patients with chronic lymphocytic leukaemia refractory to fludarabine and alemtuzumab) showed significant improvements $v$ "physician's choice" with respect to fatigue but not side effects of treatment or effects of disease. HRQoL was evaluated according to three prespecified domains of the European Organisation for Research and Treatment of Cancer Quality of Life Questionnaire C30 (EORTC-C30) and the chronic lymphocytic leukaemia module QLQ-CLL16 (fatigue, side effects of treatment, and effects of disease). The study was open label ${ }^{49}$

- Pazopanib (for first line treatment of advanced renal cell carcinoma) significantly improved HRQoL compared with sunitinib with respect to 11 of $14 \mathrm{HRQ}$ oL domains. HRQoL was assessed with the functional assessment of chronic illness therapy-fatigue (FACIT-F) questionnaire, the National Comprehensive Cancer Network/functional assessment of cancer therapy-kidney symptom index 19 (NCCN-FACT FKSI-19), and the cancer therapy satisfaction questionnaire. The study was open label ${ }^{50}$

of $20(40 \%)$ for use in the non-curative setting and all three treatments with curative intent.

\section{Results summary}

Among 68 cancer drug indications approved by the EMA in the period 2009-13, and with a median of 5.4 years' follow-up, only 35 (51\%) were associated with a significant improvement in survival $(26 / 35)$ or quality of life (9/35) over existing treatment options, placebo, or as add on treatment. Only two of the 26 drugs shown to extend life also showed benefits on quality of life, and $33(49 \%)$ had not shown any improvement on survival or quality of life (fig 2). Of the 23 drugs with a survival benefit that could be scored with the validated ESMO-MCBS tool, only 11 (48\%) were judged to offer a clinically meaningful benefit.

\section{Discussion}

\section{Summary of findings}

This systematic evaluation of oncology drug approvals by the EMA in 2009-13 shows that most of the drugs (39/68, 57\%) entered the market without evidence of improved survival or quality of life. At a minimum 3.3 years after market entry, there was still no conclusive evidence that 33 of these 39 cancer drugs either extended or improved life. Our findings suggest it is extremely rare for new studies or follow-up analyses of pivotal trials in the postmarketing period to report results confirming that new cancer drugs have a positive impact on the two most important outcomes for patients-survival and quality of life. When survival gains over existing treatment options or placebo were shown, they were often marginal and judged to be clinically meaningful in less than half $(11 / 23,48 \%)$ of all cases.

What are potential reasons for the paucity of drug approvals with demonstrable survival advantages over existing treatments? Firstly, only 18 (26\%) indications for use in our cohort were supported by trials in which extension of life was the primary outcome, and trials that evaluated survival as a secondary endpoint might not have been powered to detect differences between groups with and without the experimental treatment. Secondly, crossover from control to experimental arm after disease progression (or to similar drugs after the study) is a commonly cited reason for the lack of survival benefits in clinical trials of oncology products. ${ }^{38}$ It should be noted, however, that for some 


\begin{tabular}{|c|c|c|c|c|c|c|c|c|}
\hline Study & Drug & Site & Indication & Trial & $\begin{array}{l}\text { Overall } \\
\text { survival } \\
\text { gain*}\end{array}$ & $\mathrm{HR}(\mathrm{Cl})$ & $\begin{array}{l}\text { QoL/ } \\
\text { toxicity† }\end{array}$ & $\begin{array}{l}\text { ESMO } \\
\text { score‡ }\end{array}$ \\
\hline Fizazi $(2012)^{51}$ & Abiraterone & Prostate & $\begin{array}{l}\text { mCRPC (+pred) after } \\
\text { chemo }\end{array}$ & $\begin{array}{l}\text { COU-AA-301 (pred- } \\
\text { nisone } \pm \text { abiraterone) }\end{array}$ & 4.6 & 0.74 (0.64 to 0.86$)$ & Yes & 4 \\
\hline Ryan $(2015)^{52}$ & Abiraterone & Prostate & $\begin{array}{l}\text { mCRPC (+pred) before } \\
\text { chemo }\end{array}$ & $\begin{array}{l}\text { COU-AA-302 (abi- } \\
\text { raterone+prednisone } \\
\text { or prednisolone } v \\
\text { placebo+prednisone or } \\
\text { prednisolone) }\end{array}$ & 4.4 & 0.81 (0.70 to 0.93$)$ & Yes & 4 \\
\hline Van Cutsem (2012) ${ }^{53}$ & Aflibercept & Bowel & $\begin{array}{l}\text { 2nd line mCRC (+FOL- } \\
\text { FIRI) }\end{array}$ & $\begin{array}{l}\text { VELOUR (aflibercept, } \\
\text { then FOFIRI } v \text { placebo, } \\
\text { then FOLFIRI) }\end{array}$ & 1.44 & 0.817 (0.713 to 0.937$)$ & No & 1 \\
\hline De Bono $(2010)^{54}$ & Cabazitaxel & Prostate & $\begin{array}{l}\text { Hormone refractory } \\
\text { mPC (+pred) previously } \\
\text { treated with docetaxel }\end{array}$ & $\begin{array}{l}\text { TROPIC (cabazitax- } \\
\text { el+prednisone or } \\
\text { prednisolone } v \text { mitox- } \\
\text { antrone+prednisone or } \\
\text { prednisolone) }\end{array}$ & 2.4 & $0.70(0.59$ to 0.83$)$ & No & 2 \\
\hline Cortes $(2011)^{55}$ & Eribulin & Breast & 3rd line $\mathrm{mBC}$ & $\begin{array}{l}\text { EMBRACE (eribulin } v \\
\text { physician's choice) }\end{array}$ & 2.5 & 0.81 (0.66 to 0.99) & No & 2 \\
\hline Cappuzzo $(2010)^{56}$ & Erlotinib & Lung & $\begin{array}{l}\text { Maintenance therapy in } \\
\text { mNSCLC (previous plat- } \\
\text { inum based chemo) }\end{array}$ & $\begin{array}{l}\text { SATURN (erlotinib } v \\
\text { placebo) }\end{array}$ & 1 & 0.81 (0.70 to 0.95$)$ & No & 1 \\
\hline Scher $(2012)^{57}$ & Enzalutamide & Prostate & mCRPC after docetaxel & $\begin{array}{l}\text { AFFIRM (enzalutamide } v \\
\text { placebo) }\end{array}$ & 4.8 & $0.63(0.53$ to 0.75$)$ & Yes & 4 \\
\hline Hodi $(2010)^{58}$ & Ipilimumab & Skin & $\begin{array}{l}\text { 2nd line unresectable } \\
\text { or metastatic mela- } \\
\text { noma }\end{array}$ & $\begin{array}{l}\text { MDX010-20 (ipilimum- } \\
\text { ab } v \text { vaccine alone) }\end{array}$ & 3.7 & $0.66(0.51$ to 0.87$)$ & No & 4 \\
\hline Robert $(2011)^{59}$ & Ipilimumab & Skin & $\begin{array}{l}\text { 1st line unresectable or } \\
\text { metastatic melanoma }\end{array}$ & $\begin{array}{l}\text { CA184-024 (dacarba- } \\
\text { zine } \pm \text { ipilimumab) }\end{array}$ & 2.1 & 0.72 (0.59 to 0.87$)$ & No & 2 \\
\hline Blackwell $(2012)^{60}$ & Lapatinib & Breast & $\begin{array}{l}\text { HER2+ HR- mBC (+ } \\
\text { trastuzumab). Previous } \\
\text { trastuzumab + chemo }\end{array}$ & $\begin{array}{l}\text { EGF104900 (lapatin- } \\
\text { ib } \pm \text { trastuzumab) }\end{array}$ & 4.5 & 0.74 (0.57 to 0.97$)$ & No & 4 \\
\hline Meyers $(2008)^{61}$ & Mifamurtide & Osteosarcoma & $\begin{array}{l}\text { Resectable, non-meta- } \\
\text { static osteosarcoma af- } \\
\text { ter complete resection } \\
(+ \text { chemo) }\end{array}$ & INT-0133 & $\begin{array}{l}6 \text { years; } \\
8 \%\end{array}$ & $0.71(0.52$ to 0.96$)$ & NR & A \\
\hline Goldstein $(2015)^{62}$ & Nab-paclitaxel & Pancreatic & $\begin{array}{l}\text { 1st line (+ gemcit- } \\
\text { abine) metastatic } \\
\text { pancreatic adenoca }\end{array}$ & $\begin{array}{l}\text { CA046 (gemcitabi- } \\
\text { ne } \pm \text { nab-paclitaxel) }\end{array}$ & 2.1 & $0.72(0.62$ to 0.83$)$ & No & 2 \\
\hline Douillard $(2014)^{63}$ & Panitumumab & Bowel & $\begin{array}{l}\text { 1st line KRAS WT mCRC } \\
\text { (+ FOLFOX) }\end{array}$ & $\begin{array}{l}\text { PRIME (FOLFOX4 pani- } \\
\text { tumumab) }\end{array}$ & 4.4 & 0.83 (0.70 to 0.98$)$ & No & 3 \\
\hline Ciuleanu $(2009)^{64}$ & Pemetrexed & Lung & $\begin{array}{l}\text { Maintenance for } \\
\text { mNSCLC (non-squam) } \\
\text { after platinum based } \\
\text { doublet chemo ( } \mathrm{w} / \\
\text { gemcitabine or taxane) }\end{array}$ & $\begin{array}{l}\text { JMEN (pemetrexed+BSC } \\
\checkmark \text { placebo+BSC) }\end{array}$ & 2.8 & 0.790 .65 to 0.95$)$ & No & 3 \\
\hline Paz-Ares $(2013)^{65}$ & Pemetrexed & Lung & $\begin{array}{l}\text { Maintenance for } \\
\text { mNSCLC (non-squam) } \\
\text { after platinum based } \\
\text { chemo }\end{array}$ & $\begin{array}{l}\text { PARAMOUNT (peme- } \\
\text { trexed+BSC } v \text { place- } \\
\text { bo+BSC) }\end{array}$ & 2.9 & 0.78 (0.64 to 0.96$)$ & No & 3 \\
\hline Swain $(2015)^{66}$ & Pertuzumab & Breast & 1st line HER2 + mBC & $\begin{array}{l}\text { CLEOPATRA (trastuzuma- } \\
\text { b+chemo } \pm \text { pertuzumab) }\end{array}$ & 15.7 & 0.68 (0.56 to 0.84$)$ & No & 4 \\
\hline Grothey $(2013)^{67}$ & Regorafenib & Bowel & $\begin{array}{l}\text { mCRC either after pre- } \\
\text { vious treatment with/ } \\
\text { or ineligible for } 5 \mathrm{FU} \text { - } \\
\text { based chemo or VEGFi } \\
\text { or EGFRi therapy }\end{array}$ & $\begin{array}{l}\text { CORRECT (regorafenib } v \\
\text { placebo) }\end{array}$ & 1.4 & 0.77 (0.64 to 0.94) & No & 1 \\
\hline Bang $(2010)^{68}$ & Trastuzumab & Stomach & $\begin{array}{l}\text { 1st line HER2+ mGC or } \\
\text { mGOJ adenoca }\end{array}$ & $\begin{array}{l}\text { ToGA (5-FU or capecit- } \\
\text { abine+cisplatin士trastu- } \\
\text { zumab) }\end{array}$ & 2.7 & 0.74 (0.60 to 0.91$)$ & No & 3 \\
\hline Perez $(2014)^{69}$ & Trastuzumab & Breast & $\begin{array}{l}\text { HER2+ BC (+taxane) } \\
\text { after adjuvant chemo }\end{array}$ & $\begin{array}{l}\text { NASBP-31 and } \\
\text { NCCTG-N9831 (dox- } \\
\text { orubicin+cyclophos- } \\
\text { phamide, followed by } \\
\text { paclitaxel_trastuzumab) }\end{array}$ & $\begin{array}{l}10 \text { years; } \\
8.8 \%\end{array}$ & $0.63(0.54$ to 0.73$)$ & NR & A \\
\hline Slamon $(2011)^{70}$ & Trastuzumab & Breast & $\begin{array}{l}\text { HER2+ BC (+adjuvant } \\
\text { chemo) }\end{array}$ & $\begin{array}{l}\text { BCIRG-006 (doxo- } \\
\text { rubicin+cyclophos- } \\
\text { phamide, followed } \\
\text { by trastuzumab } v \\
\text { doxorubicin+cyclophos- } \\
\text { phamide, followed by } \\
\text { docetaxel) }\end{array}$ & $\begin{array}{l}5.4 \text { years; } \\
5 \%\end{array}$ & 0.63 (NR) & No & B \\
\hline
\end{tabular}




\begin{tabular}{|c|c|c|c|c|c|c|c|c|}
\hline Study & Drug & Site & Indication & Trial & $\begin{array}{l}\text { Overall } \\
\text { survival } \\
\text { gain* }\end{array}$ & $\mathrm{HR}(\mathrm{CI})$ & $\begin{array}{l}\text { QoL/ } \\
\text { toxicity† }\end{array}$ & $\begin{array}{l}\text { ESMO } \\
\text { score }\end{array}$ \\
\hline Verma $(2012)^{71}$ & $\begin{array}{l}\text { Trastuzumab } \\
\text { emtansine }\end{array}$ & Breast & $\begin{array}{l}\text { HER2 + unresectable or } \\
\text { mBC after trastuzumab } \\
\text { and/or taxane }\end{array}$ & $\begin{array}{l}\text { EMILIA (trastuzumab } \\
\text { emanstine } v \text { lapatinib+- } \\
\text { capecitabine) }\end{array}$ & 5.8 & $0.68(0.55$ to 0.85$)$ & Yes & 5 \\
\hline McArthur $(2014)^{72}$ & Vemurafenib & Skin & $\begin{array}{l}\text { Unresectable or meta- } \\
\text { static melanoma (BRAF } \\
\text { V600 mut) }\end{array}$ & $\begin{array}{l}\text { BRIM-3 (vemurafenib } v \\
\text { dacarbazine) }\end{array}$ & 3.9 & $0.70(0.57$ to 0.87$)$ & No & 4 \\
\hline Bellmunt $(2009)^{73}$ & Vinflunine & Urinary & $\begin{array}{l}\text { Advanced or metastatic } \\
\text { TCC of urothelial tract. } \\
\text { Previous platinum } \\
\text { regimen }\end{array}$ & $\begin{array}{l}\text { VFL-302 (vinflunine+B- } \\
\text { SC } v \text { BSC) }\end{array}$ & 2.6 & 0.77 (0.61 to 0.99) & No & 3 \\
\hline
\end{tabular}

See box 1 for abbreviations.

* Survival gain in months, or percent of patients surviving at x years.

†Yes=quality of life or improved toxicity reported; no=no quality of life gain or improvement in toxicity reported, or toxicity might be worse.

FFor drug indications with curative intent, grade of A or B indicates trial data show drug offers clinically meaningful benefit. For drug indications with non-curative intent, grade of 4 or 5 indicates

trial data show drug offers clinically meaningful benefit. For drugs with non-curative intent, grade of 1 , 2, or 3 indicates drug does not reach ESMO threshold for clinically meaningful benefit.

indications for use in our cohort there were no survival gains even in the absence of crossover. ${ }^{75074-76}$

None of the pivotal studies supporting oncology drug approvals from 2009 to 2013 included quality of life as a primary outcome measure. This is perhaps unsurprising as the EMA does not require marketing authorisation holders to evaluate quality of life, even when drugs are intended for late line palliative care. ${ }^{77}$ Of the 68 (54\%) study indications, 37 were supported by a pivotal trial in which quality of life was evaluated as a secondary endpoint, and for only seven (10\%) was there a significant improvement in quality of life at time of market entry. Neither the EPARs nor the published studies were consistent in reporting whether significant improvements for specific quality of life outcomes were also clinically relevant. These are particularly troubling findings as many of the drugs in our sample were approved to treat advanced metastatic disease, when the purpose of treatment is palliativethat is, to improve quality of life-or to extend life while ensuring that any survival gains are not outweighed by a deterioration in quality of life from adverse events or other negative factors related to treatment. ${ }^{7879}$

A significant minority of drugs in our sample $(8 / 68$, $12 \%$ ) were approved solely on the basis of a single arm study. Most of the indications supported by single arm studies (6/8) were granted orphan designation, and it is recognised that the conduct of randomised trials to investigate treatments for rare cancers can be challenging. Nevertheless, a review of FDA approvals indicates that randomised controlled trials are feasible even in rare cancers with an incidence of less than $1 / 100000$ /year. $^{80}$

\section{Comparison with other studies}

Apolone and colleagues ${ }^{27}$ evaluated the evidence base for new cancer drugs approved by the EMA in the period 1995-2004. In that 10 year period the EMA authorised 14 anticancer drugs for 27 indications. An important difference between their earlier study and the present one is that the earlier cohort includes only drugs to treat solid tumours. Nevertheless, our findings indicate some improvements in the quality of the evidence base supporting new oncology drugs.
For example, drug uses authorised in the study period 2009-13 were more likely to be supported by trials that included overall survival as a primary endpoint $(26 \% \mathrm{~V}$ $8 \%$ ), and by randomised trials ( $88 \% v 66 \%)$. There has been a substantial increase in the number of approved treatments for solid tumours compared with the earlier period-an average of 12 a year for 2009-20 compared with three a year for 1995-2004.

In contrast with recent studies focusing on a subset of oncology drug approvals in Europe, ${ }^{3233}$ we included all authorised oncology indications regardless of route of approval and systematically analysed survival and quality of life benefits. We also relied exclusively on evidence generated from randomised controlled trials. We did not therefore accept mathematical models considered by health technology assessment bodies such as the National Institute for Health and Care Excellence. ${ }^{81}$ There is continuing debate around the validity of simulation models that extrapolate findings from short term trials. ${ }^{82} 83$ Our analysis is the first to investigate whether drugs that did not show a survival benefit at the time of approval in Europe are subsequently shown to improve survival or quality of life in follow-up randomised controlled trials once drugs are on the market.

\section{Study limitations}

There are several limitations to this study. Firstly, there were several cases in which results reported in the EPARs were ambiguous or incomplete. When difficulties in interpretation occurred, we ensured our determinations were consistent with the EMA's conclusions. Following this approach, we determined that significant survival benefits had been shown at time of market authorisation for vinflunine (in transitional cell carcinoma) and trastuzumab (in neoadjuvant breast cancer), despite uncertainty regarding the reported statistical analyses. When the EMA's opinions on specific questions were not clear or not available, we adopted a generous approach that favoured the drug. For example, we credited panitumumab with showing a survival benefit in the postmarketing period on the basis of an "exploratory" analysis. $^{84}$ 
There was also considerable variation in the reporting of quality of life endpoints in both the EPARs and the medical literature. Significant results might have been shown for isolated parameters or single subscales only, and it was not clear whether a net quality of life benefit had been shown. Nor was it consistently reported whether or not the magnitude of improvement was such that it would be considered clinically meaningful for patients. Consequently, we might have overestimated the proportion of drugs that offer benefits on survival or quality of life and the clinical meaningfulness of these. Our findings, however, are consistent with recent findings from the US. ${ }^{30} 85$

Secondly, we did not consider the appropriateness of clinical trial design, including whether a treatment administered in the control arm of a study was optimal or even informative. This is an important study limitation, which again means we might have overestimated the benefits offered by the drugs in our sample. For example, the control arm of the pivotal trial to support approval of ipilimumab for metastatic melanoma was an experimental treatment. Similarly, the pivotal trial to support lapatinib in combination with trastuzumab for patients with metastatic breast cancer used lapatinib monotherapy as the comparison-a treatment acknowledged in the EPAR to be "without established efficacy." 86 Although this trial design failed to isolate the effects of the test drug, the EMA nevertheless concluded that the reported benefit in survival was clinically relevant and could be attributed to the combination.

Thirdly, our ESMO ratings share the limitations of the published studies on which they are based. For example, the magnitude of clinical benefit shown in a particular trial could be inflated by the choice of an inappropriate comparator or treatment in the control arm that does not represent best standard of care. ${ }^{38}$ Several maintenance therapy trials for metastatic non-small cell lung cancer, for example, have been criticised for flawed study designs that systematically result in substandard care in the control arms. ${ }^{87}$ In the case of lapatinib combined with tratuzumab, the pivotal study was scored 4 on the basis of a 4.5 month survival gain over lapatinib monotherapy (with no established efficacy).

Fourthly, our findings do not reflect the totality of the evidence base for a specific authorised indication as we did not take account of studies with negative results for the same drug indication if they were not reported as pivotal studies in the EPAR, nor did we take account of the fact that studies with positive results for a particular indication could conflict with negative findings from other studies in the same indicated patient population.

\section{Implications for clinical practice and regulatory policy}

Despite the EMA's statement that overall survival is the "most persuasive outcome" for studies investigating the clinical safety and efficacy of new oncology drugs and new uses of such drugs, European regulators commonly accept the use of surrogate measures of drug benefit as primary endpoints in pivotal trials for both conditional and regular pathways to market authorisation. ${ }^{1188}$ In addition, any demonstration of a statistically significant difference in survival between treatments, however small and regardless of whether such a difference is clinically meaningful to patients, has recently been accepted as the basis for approving new cancer drugs. ${ }^{89}$ To a large extent, regulatory evidence standards determine the clinical value of, and the quality of the evidence base for, new oncology drugs. Our study suggests these standards are failing to incentivise drug development that best meets the needs of patients, clinicians, and healthcare systems. 15171921

Though surrogate endpoints are argued to have the advantage of allowing quicker drug development and patient access, it is questionable whether studies based on surrogate measures of efficacy provide optimal, or even meaningful, information for patients and clinicians. ${ }^{24}$ Moreover, our analysis raises the possibility that regulatory and current research practices have created a situation in which critical information about the outcomes that matter most to patients might never be generated once oncology drugs are approved for widespread use. The limited availability of studies showing either benefits to overall survival or quality of life in the postmarketing period underscores the importance of requiring robust evidence of clinical benefit at the time of marketing authorisation. $^{90-92}$

The EMA and other drug regulatory agencies should reconsider when, and to what extent, it is appropriate to approve new cancer drugs on the basis of surrogate endpoints. Furthermore, when gains in survival and quality of life are shown, these gains should be meaningful to patients and clinicians.

\section{Conclusion}

Among 68 cancer drug indications approved by the EMA in the period 2009-13, and with a median of 5.4 years' follow-up, only 35 (51\%) were associated with significant improvement in survival or quality of life over alternative treatment options, placebo, or as add on treatment. For 33 (49\%), uncertainty remains over whether the drugs extend survival or improve quality of life. Of the 23 drugs with a survival benefit that could be scored with the validated ESMO-MCBS tool, only 11 (48\%) were judged to offer a clinically meaningful benefit.

Most new oncology drugs authorised by the EMA in 2009-13 came onto the market without clear evidence that they improved the quality or quantity of patients' lives, and, when survival gains over available treatment alternatives were shown, they were not always clinically meaningful. Little new information to guide patients, their treating clinicians, or decisions about whether or not to pay for treatments was generated in the postmarketing period. This situation has negative implications for patients and 
public health. ${ }^{1993}$ When expensive drugs that lack clinically meaningful benefits are approved and paid for within publicly funded healthcare systems, individual patients can be harmed, important societal resources wasted, and the delivery of equitable and affordable care undermined.

Contributors: $C D$ conceived the study and acquired funding. $C D$, $\mathrm{HN}$, and AA designed the study. EP, AP, and EG undertook data extraction and some analysis. $C D$ undertook the primary analysis with input from $\mathrm{HN}$ and $\mathrm{AA}$. CD drafted the first manuscript, with $\mathrm{HN}$ and $A A$ contributing to subsequent iterations. All authors provided critical input on the manuscript and approved the final version for publication. CD is guarantor.

Funding: This study was supported by project funding from Health Action International. The study funder did not have any role in the study design; the collection, analysis, and interpretation of data; the writing of the report; or the decision to submit the article for publication. CD is a member of Health Action International Europe Members Association. EP is a member of Health Projects for Latvia, which is affiliated to Health Action International, and a board member of the Health Action International Europe Association. All authors had full access to all of the data in the study and can take responsibility for the integrity of the data and the accuracy of the data analysis.

Competing interests: All authors have completed the ICMJE uniform disclosure at www.icmje.org/coi_disclosure.pdf and declare: EG, AP, and EP were supported by project funding from Health Action International; no financial relationships with any organisations that might have an interest in the submitted work in the previous three years; no other relationships or activities that could appear to have influenced the submitted work.

Ethical approval: Not required.

Data sharing: No additional data available.

Transparency: The lead author affirms that this manuscript is an honest, accurate and transparent account of the study being reported; that no important aspects of the study have been omitted; and that any discrepancies from the study as planned have been explained.

This is an Open Access article distributed in accordance with the Creative Commons Attribution Non Commercial (CC BY-NC 4.0) license, which permits others to distribute, remix, adapt, build upon this work non-commercially, and license their derivative works on different terms, provided the original work is properly cited and the use is noncommercial. See: http://creativecommons.org/licenses/by-nc/4.0/

1 Peppercorn JM, Smith TJ, Helft PR, et al. American Society of Clinical Oncology. American society of clinical oncology statement: toward individualized care for patients with advanced cancer. / Clin Oncol 2011;29:755-60. doi:10.1200/JCO.2010.33.1744

2 Tannock IF, Amir E, Booth CM, et al. Relevance of randomised controlled trials in oncology. Lancet Oncol 2016;17:e560-7. doi:10.1016/S1470-2045(16)30572-1

3 Wilson MK, Collyar D, Chingos DT, et al. Outcomes and endpoints in cancer trials: bridging the divide. Lancet Oncol 2015;16:e43-52. doi:10.1016/S1470-2045(14)70380-8

4 Amir E, Seruga B, Kwong R, Tannock IF, Ocaña A. Poor correlation between progression-free and overall survival in modern clinical trials: are composite endpoints the answer? Eur Cancer 2012;48:385-8. doi:10.1016/j.ejca.2011.10.028

5 Blumenthal GM, Karuri SW, Zhang H, et al. Overall response rate, progression-free survival, and overall survival with targeted and standard therapies in advanced non-small-cell lung cancer: US Food and Drug Administration trial-level and patient-level analyses. J Clin Oncol 2015;33:1008-14. doi:10.1200/JCO.2014.59.0489

6 Booth CM, Eisenhauer EA. Progression-free survival: meaningful or simply measurable? J Clin Oncol 2012;30:1030-3. doi:10.1200/ JCO.2011.38.7571

7 Piccart M, Hortobagyi GN, Campone M, et al. Everolimus plus exemestane for hormone-receptor-positive, human epidermal growth factor receptor-2-negative advanced breast cancer: overall survival results from BOLERO-2. Ann Oncol 2014;25:2357-62. doi:10.1093/ annonc/mdu456

8 Prasad V, Kim C, Burotto M, Vandross A. The Strength of Association Between Surrogate End Points and Survival in Oncology: A Systematic Review of Trial-Level Meta-analyses. JAMA Intern Med 2015;175:1389-98. doi:10.1001/jamainternmed.2015.2829

9 Saad ED, Katz A, Buyse M. Overall survival and post-progression survival in advanced breast cancer: a review of recent randomized clinical trials. J Clin Oncol 2010;28:1958-62. doi:10.1200/ JCO.2009.25.5414
10 Wilkerson J, Fojo T. Progression-free survival is simply a measure of a drug's effect while administered and is not a surrogate for overall survival. Cancer / 2009;15:379-85. doi:10.1097/ PPO.0b013e3181bef8cd

11 US Department of Health and Human Service, FDA, CDER, CBER Guidance for Industry: Clinical Trial Endpoints for the Approval of Cancer Drugs and Biologics. 2007. https://www.fda.gov/downloads/ Drugs/Guidances/ucm071590.pdf

12 Miller K, Wang M, Gralow J, et al. Paclitaxel plus bevacizumab versus paclitaxel alone for metastatic breast cancer. $N$ Engl J Med 2007;357:2666-76. doi:10.1056/NEJMoa072113

13 Gutman SI, Piper M, Grant MD, et al. Progression-Free Survival: What Does It Mean for Psychological Well-Being or Quality of Life? Rockville (MD), 2013.

14 Ciani O, Davis S, Tappenden P, et al. Validation of surrogate endpoints in advanced solid tumors: systematic review of statistical methods, results, and implications for policy makers. Int J Technol Assess Health Care 2014;30:312-24. doi:10.1017/ S0266462314000300

15 Davis C. Drugs, cancer and end-of-life care: a case study of pharmaceuticalization? Soc Sci Med 2015;131:207-14. doi:10.1016/j.socscimed.2014.12.007

16 Fojo T, Grady C. How much is life worth: cetuximab, non-small cell lung cancer, and the $\$ 440$ billion question. J Natl Cancer Inst 2009;101:1044-8. doi:10.1093/jnci/djp177

17 Ocana A, Tannock IF. When are "positive" clinical trials in oncology truly positive?/ Natl Cancer Inst 2011;103:16-20. doi:10.1093/jnci/ djq463

18 Saltz LB. Progress in cancer care: the hope, the hype, and the gap between reality and perception. J Clin Oncol 2008;26:5020-1. doi:10.1200/JCO.2008.17.6198

19 Aggarwal A, Fojo T, Chamberlain C, Davis C, Sullivan R. Do patient access schemes for high-cost cancer drugs deliver value to society?lessons from the NHS Cancer Drugs Fund. Ann Oncol 2017;28:1738 50. doi:10.1093/annonc/mdx110

20 Booth CM, Cescon DW, Wang L, Tannock IF, Krzyzanowska MK. Evolution of the randomized controlled trial in oncology over three decades. J Clin Oncol 2008;26:5458-64. doi:10.1200/ CO.2008.16.5456

21 Fojo T, Mailankody S, Lo A. Unintended consequences of expensive cancer therapeutics - the pursuit of marginal indications and a metoo mentality that stifles innovation and creativity: the John Conley Lecture. IAMA Otolaryngol Head Neck Surg 2014;140:1225-36. doi:10.1001/jamaoto.2014.1570

22 Kantarjian HM, Fojo T, Mathisen M, Zwelling LA. Cancer drugs in the United States: Justum Pretium--the just price. J Clin Oncol 2013;31:3600-4. doi:10.1200/JCO.2013.49.1845

23 Light DW, Lexchin J. Why do cancer drugs get such an easy ride? BMJ 2015;350:h2068. doi:10.1136/bmj.h2068

24 Booth CM, Del Paggio JC. Approvals in 2016: questioning the clinical benefit of anticancer therapies. Nat Rev Clin Oncol 2017;14:135-6. doi:10.1038/nrclinonc.2017.18

25 Dangoor A, Joffe J, Januszewski A, Mansi J, Cunningham D, Selby P. 17 other authors and members of the Association of Cancer Physicians, UK. The Association of Cancer Physicians responds to "Cancer drugs, survival, and ethics". BM/ 2016;355:i6487. https://doi.org/10.1136/bmj.i5792. doi:10.1136/bmj.i6487

26 Naci H, Cylus J, Vandoros S, Sato A, Perampaladas K. Raising the bar for market authorisation of new drugs. BMJ 2012;345:e4261. doi:10.1136/bmj.e4261

27 Apolone G, Joppi R, Bertele’ V, Garattini S. Ten years of marketing approvals of anticancer drugs in Europe: regulatory policy and guidance documents need to find a balance between different pressures. BrJ Cancer 2005;93:504-9. doi:10.1038/sj.bjc. 6602750

28 Garattini S, Bertele V. Efficacy, safety, and cost of new anticancer drugs. BMJ 2002;325:269-71. doi:10.1136/bmj.325.7358.269

29 Pignatti F, Aronsson B, Vamvakas S, et al. Clinical trials for registration in the European Union: the EMEA 5-year experience in oncology. Crit Rev Oncol Hematol 2002;42:123-35. doi:10.1016/S10408428(02)00009-4

30 Kim C, Prasad V. Cancer Drugs Approved on the Basis of a Surrogate End Point and Subsequent Overall Survival: An Analysis of 5 Years of US Food and Drug Administration Approvals. JAMA Intern Med 2015;175:1992-4. doi:10.1001/ jamainternmed.2015.5868

31 Hatswell AJ, Baio G, Berlin JA, Irs A, Freemantle N. Regulatory approval of pharmaceuticals without a randomised controlled study: analysis of EMA and FDA approvals 1999-2014. BMJ Open 2016:6:e011666. doi:10.1136/bmjopen-2016-011666

32 Hoekman J, Boon WP, Bouvy JC, Ebbers HC, de Jong JP, De Bruin ML. Use of the conditional marketing authorization pathway for oncology medicines in Europe. Clin Pharmacol Ther 2015;98:534-41. doi:10.1002/cpt.174 
33 Martinalbo J, Bowen D, Camarero J, et al. Early market access of cancer drugs in the EU. Ann Oncol 2016;27:96-105. doi:10.1093/ annonc/mdv506

34 Tafuri G, Stolk P, Trotta F, et al. How do the EMA and FDA decide which anticancer drugs make it to the market? A comparative qualitative study on decision makers' views. Ann Oncol 2014;25:265-9. doi:10.1093/annonc/mdt512

35 Trotta F, Leufkens HG, Schellens JH, Laing R, Tafuri G. Evaluation of oncology drugs at the European Medicines Agency and US Food and Drug Administration: when differences have an impact on clinical practice. J Clin Oncol 2011;29:2266-72. doi:10.1200/ ICO.2010.34.1248

36 Official Journal of the European Union. Commission Regulation (EC) No. 507/2006, of 29 March 2006 on the conditional marketing authorisation for medicinal products for human use falling within the scope of Regulation (EC) No 726/2004 of the European Parliament and of the Council, 2006

37 Higgins JPT Green S. Cochrane Handbook for Systematic Reviews of Interventions Version 5.1.0 (updated March 2011). Cochrane Collaboration, 2011. 2011

38 Cherny NI, Sullivan R, Dafni U, et al. A standardised, generic, validated approach to stratify the magnitude of clinical benefit that can be anticipated from anti-cancer therapies: the European Society for Medical Oncology Magnitude of Clinical Benefit Scale (ESMO-MCBS). Ann Oncol 2015;26:1547-73. doi:10.1093/annonc/mdv249

39 ESMO. Magnitude of Clinical Benefit Scale. http://www.esmo.org/ Policy/Magnitude-of-Clinical-Benefit-Scale/Scale-Evaluation-Forms.

40 EMA. EMA/CHMP/815425/2010, 16 December 2010. 2010

41 Gianni L, Eiermann W, Semiglazov V, et al. Neoadjuvant and adjuvan trastuzumab in patients with HER2-positive locally advanced breast cancer (NOAH): follow-up of a randomised controlled superiority tria with a parallel HER2-negative cohort. Lancet Oncol 2014;15:640-7. doi:10.1016/S1470-2045(14)70080-4

42 Guérin A, Chen L, Ionescu-Ittu R, et al. Impact of low-grade adverse events on health-related quality of life in adult patients receiving imatinib or nilotinib for newly diagnosed Philadelphia chromosome positive chronic myelogenous leukemia in chronic phase. Curr Med Res Opin 2014;30:2317-28. doi:10.1185/03007995.2014.944973

43 EMA. EMEA/H/C/002280. http://www.ema.europa.eu/docs/ en_GB/document_library/EPAR_-_Public_assessment_report/ human/002280/WC500152394.pdf.

44 EMA. EMEA/H/C/001016. http://www.ema.europa.eu/docs/ en_GB/document_library/EPAR___Public_assessment_report/ human/001016/WC500036361.pdf.

45 EMA. EMEA/H/C/0001242. http://www.ema.europa.eu/docs/ en GB/document library/EPAR - Public assessment report/ human/001242/WC500104417.pdf.

46 EMA. EMEA/H/C/002315/0000. http://www.ema.europa.eu/docs/ en GB/document library/EPAR - Public assessment report/ human/002315/WC500123603.pdf.

47 Shaw AT, Kim DW, Nakagawa K, et al. Crizotinib versus chemotherapy in advanced ALK-positive lung cancer. N Engl J Med 2013;368:238594. doi:10.1056/NEJMoa1214886

48 Chen G, Feng J, Zhou C, et al. Quality of life (QoL) analyses from OPTIMAL (CTONG-0802), a phase III, randomised, open-label study of first-line erlotinib versus chemotherapy in patients with advanced EGFR mutation-positive non-small-cell lung cancer (NSCLC). Ann Oncol 2013;24:1615-22. doi:10.1093/annonc/mdt012

49 Österborg A, Udvardy M, Zaritskey A, et al. Phase III, randomized study of ofatumumab versus physicians' choice of therapy and standard versus extended-length ofatumumab in patients with bulky fludarabine-refractory chronic lymphocytic leukemia. Leuk Lymphoma 2016;57:2037-46. doi:10.3109/10428194.2015. 1122783

50 Motzer RJ, Hutson TE, Cella D, et al. Pazopanib versus sunitinib in metastatic renal-cell carcinoma. N Engl J Med 2013;369:722-31. doi:10.1056/NEJMoa1303989

51 Fizazi K, Scher HI, Molina A. COU-AA-301 Investigators. Abiraterone acetate for treatment of metastatic castration-resistant prostate cancer: final overall survival analysis of the COU-AA-301 randomised, double-blind, placebo-controlled phase 3 study. Lancet Oncol 2012;13:983-92. doi:10.1016/S1470-2045(12)70379-0

52 Ryan CJ, Smith MR, Fizazi K, et al. COU-AA-302 Investigators. Abiraterone acetate plus prednisone versus placebo plus prednisone in chemotherapy-naive men with metastatic castrationresistant prostate cancer (COU-AA-302): final overall survival analysis of a randomised, double-blind, placebo-controlled phase 3 study. Lancet Oncol 2015;16:152-60. doi:10.1016/S14702045(14)71205-7

53 Van Cutsem E, Tabernero J, Lakomy R, et al. Addition of aflibercept to fluorouracil, leucovorin, and irinotecan improves survival in a phase III randomized trial in patients with metastatic colorectal cancer previously treated with an oxaliplatin-based regimen. J Clin Oncol 2012;30:3499-506. doi:10.1200/ JCO.2012.42.8201
54 de Bono JS, Oudard S, Ozguroglu M, et al. TROPIC Investigators. Prednisone plus cabazitaxel or mitoxantrone for metastatic castrationresistant prostate cancer progressing after docetaxel treatment: a randomised open-label trial. Lancet 2010;376:1147-54. doi:10.1016 S0140-6736(10)61389-X

55 Cortes J, O'Shaughnessy J, Loesch D, et al. EMBRACE (Eisai Metastatic Breast Cancer Study Assessing Physician's Choice Versus E7389) investigators. Eribulin monotherapy versus treatment of physician's choice in patients with metastatic breast cancer (EMBRACE): a phase 3 open-label randomised study. Lancet 2011;377:914-23. doi:10.1016/S0140-6736(11)60070-6

56 Cappuzzo F, Ciuleanu T, Stelmakh L, et al. SATURN investigators. Erlotinib as maintenance treatment in advanced non-small-cell lung cancer: a multicentre, randomised, placebo-controlled phase 3 study. Lancet Oncol 2010;11:521-9. doi:10.1016/S1470-2045(10)70112-1

57 Scher HI, Fizazi K, Saad F, et al. AFFIRM Investigators. Increased survival with enzalutamide in prostate cancer after chemotherapy. $N$ Engl I Med 2012;367:1187-97. doi:10.1056/NEJMoa1207506

58 Hodi FS, O'Day SJ, McDermott DF, et al. Improved survival with ipilimumab in patients with metastatic melanoma. N Engl J Med 2010;363: 711-23. doi:10.1056/NEJMoa1003466

59 Robert C, Thomas L, Bondarenko I, et al. Ipilimumab plus dacarbazine for previously untreated metastatic melanoma. $N$ Engl Med 2011;364:2517-26. doi:10.1056/NEJMoa1104621

60 Blackwell KL, Burstein HJ, Storniolo AM, et al. Overall survival benefit with lapatinib in combination with trastuzumab for patients with human epidermal growth factor receptor 2-positive metastatic breast cancer: final results from the EGF104900 Study. I Clin Oncol 2012;30: 2585-92. doi:10.1200/JCO.2011.35.6725

61 Meyers PA, Schwartz CL, Krailo MD, et al. Children's Oncology Group. Osteosarcoma: the addition of muramyl tripeptide to chemotherapy improves overall survival--a report from the Children's Oncology Group. J Clin Oncol 2008;26:633-8. doi:10.1200/ JCO.2008.14.0095

62 Goldstein D, El-Maraghi RH, Hammel P, et al. nab-Paclitaxel plus gemcitabine for metastatic pancreatic cancer: long-term survival from a phase III trial. J Natl Cancer Inst 2015;107:dju413. doi:10.1093/ jnci/dju413

63 Douillard JY, Siena S, Cassidy J, et al. Final results from PRIME: randomized phase III study of panitumumab with FOLFOX 4 for first-line treatment of metastatic colorectal cancer. Ann Oncol 2014;25:1346-55. doi:10.1093/annonc/mdu141

64 Ciuleanu T, Brodowicz T, Zielinski C, et al. Maintenance pemetrexed plus best supportive care versus placebo plus best supportive care for non-small-cell lung cancer: a randomised, double-blind, phase 3 study. Lancet 2009;374:1432-40. doi:10.1016/ S0140-6736(09)61497-5

65 Paz-Ares LG, de Marinis F, Dediu M, et al. PARAMOUNT: Final overall survival results of the phase III study of maintenance pemetrexed versus placebo immediately after induction treatment with pemetrexed plus cisplatin for advanced nonsquamous non-smallcell lung cancer. J Clin Oncol 2013;31:2895-902. doi:10.1200/ JCO.2012.47.1102

66 Swain SM, Baselga J, Kim SB, et al. CLEOPATRA Study Group. Pertuzumab, trastuzumab, and docetaxel in HER2-positive metastatic breast cancer. N Engl J Med 2015;372:724-34. doi:10.1056/ NEJMoa1413513

67 Grothey A, Van Cutsem E, Sobrero A, et al. CORRECT Study Group. Regorafenib monotherapy for previously treated metastatic colorectal cancer (CORRECT): an international, multicentre, randomised, placebo-controlled, phase 3 trial. Lancet 2013;381:303-12. doi:10.1016/S0140-6736(12)61900-X

68 Bang YJ, Van Cutsem E, Feyereislova A, et al. ToGA Trial Investigators. Trastuzumab in combination with chemotherapy versus chemotherapy alone for treatment of HER2-positive advanced gastric or gastro-oesophageal junction cancer (ToGA): a phase 3, open-label, randomised controlled trial. Lancet 2010;376:687-97. doi:10.1016/ S0140-6736(10)61121-X

69 Perez EA, Romond EH, Suman VJ, et al. Trastuzumab plus adjuvant chemotherapy for human epidermal growth factor receptor 2-positive breast cancer: planned joint analysis of overall survival from NSABP B-31 and NCCTG N9831. J Clin Oncol 2014;32:3744-52. doi:10.1200/JCO.2014.55.5730

70 Slamon D, Eiermann W, Robert N, et al. Breast Cancer International Research Group. Adjuvant trastuzumab in HER2-positive breast cancer. N Engl / Med 2011;365:1273-83. doi:10.1056/ NEJMoa0910383

71 Verma S, Miles D, Gianni L, et al. EMILIA Study Group. Trastuzumab emtansine for HER2-positive advanced breast cancer. N EnglJ Med 2012:367:1783-91. doi:10.1056/NEIMoa1209124

72 McArthur GA, Chapman PB, Robert C, et al. Safety and efficacy of vemurafenib in BRAF(V600E) and BRAF(V600K) mutation-positive melanoma (BRIM-3): extended follow-up of a phase 3, randomised, open-label study. Lancet Oncol 2014;15:323-32. doi:10.1016/ S1470-2045(14)70012-9 
73 Bellmunt J, Théodore C, Demkov T, et al. Phase III trial of vinflunine plus best supportive care compared with best supportive care alone after a platinum-containing regimen in patients with advanced transitional cell carcinoma of the urothelial tract. J Clin Oncol 2009;27:4454-61. doi:10.1200/JC0.2008.20.5534

74 Miles DW, Chan A, Dirix LY, et al. Phase III study of bevacizumab plus docetaxel compared with placebo plus docetaxel for the first-line treatment of human epidermal growth factor receptor 2-negative metastatic breast cancer. J Clin Oncol 2010;28:3239-47. doi:10.1200/JCO.2008.21.6457

75 Oza AM, Cook AD, Pfisterer J, et al. ICON7 trial investigators. Standard chemotherapy with or without bevacizumab for women with newly diagnosed ovarian cancer (ICON7): overall survival results of a phase 3 randomised trial. Lancet Oncol 2015;16:928-36. doi:10.1016/ S1470-2045(15)00086-8

76 Robert NJ, Diéras V, Glaspy J, et al. RIBBON-1: randomized, doubleblind, placebo-controlled, phase III trial of chemotherapy with or without bevacizumab for first-line treatment of human epidermal growth factor receptor 2-negative, locally recurrent or metastatic breast cancer. J Clin Oncol 2011;29:1252-60. doi:10.1200/ JCO.2010.28.0982

77 European Medicines Agency. Appendix 2 to the guideline on the evaluation of anticancer medicinal products in man. The use of patient-reported outcome measures in oncology studies. EMA/ CHMP/292464/2014, 2014

78 Braga S. Why do our patients get chemotherapy until the end of life?Ann Oncol 2011;22:2345-8. doi:10.1093/annonc/mdr416

79 Doyle C, Crump M, Pintilie M, Oza AM. Does palliative chemotherapy palliate? Evaluation of expectations, outcomes, and costs in women receiving chemotherapy for advanced ovarian cancer J Clin Oncol 2001;19:1266-74. doi:10.1200/JC0.2001.19. 5.1266

80 Gaddipati H, Liu K, Pariser A, Pazdur R. Rare cancer trial design: lessons from FDA approvals. Clin Cancer Res 2012;18:5172-8. doi:10.1158/1078-0432.CCR-12-1135

81 Salas-Vega S, Mossialos E. Cancer Drugs Provide Positive Value In Nine Countries, But The United States Lags In Health Gains Per Dollar Spent. Health Aff (Millwood) 2016;35:813-23. doi:10.1377/ hlthaff.2015.1453
82 Prasad V. Overestimating the benefit of cancer drugs. JAMA Oncol 2017. doi:10.1001/jamaoncol.2017.0107

83 Salas-Vega S, Mossialos E. Overestimating the Benefit of Cancer Drugs-Reply. JAMA Oncol 2017. doi:10.1001/jamaoncol.2017.1976

84 Douillard JY, Siena S, Cassidy J, et al. Final results from PRIME: randomized phase III study of panitumumab with FOLFOX4 for first-line treatment of metastatic colorectal cancer. Ann Oncol 2014;25:1346-55. doi:10.1093/annonc/mdu141

85 Rupp T, Zuckerman D. Quality of Life, Overall Survival, and Costs of Cancer Drugs Approved Based on Surrogate Endpoints. JAMA Intern Med 2017;177:276-7. doi:10.1001/jamainternmed.2016.7761

86 EMA. EMA, EMEA/H/C/000795/II/0022 pp 47-48.

87 Murray N. Reality check for pemetrexed and maintenance therapy in advanced non-small-cell lung cancer. J Clin Oncol 2014;32:482-3. doi:10.1200/JCO.2013.53.3448

88 EMA. Guideline on the evaluation of anticancer medicinal products in man. EMA/CHMP/205/95/Rev4 13 December 20122012

89 Pazdur R. Endpoints for assessing drug activity in clinical trials. Oncologist 2008;13(Suppl 2):19-21. doi:10.1634/ theoncologist.13-S2-19

$90 \mathrm{Naci} \mathrm{H}$, Smalley KR, Kesselheim AS. Characteristics of Preapproval and Postapproval Studies for Drugs Granted Accelerated Approval by the US Food and Drug Administration[published Online First: 2017/08/16]. JAMA 2017:318:626-36 doi:10.1001/ jama.2017.9415

91 Naci H, Wouters OJ, Gupta R, loannidis JPA. Timing and Characteristics of Cumulative Evidence Available on Novel Therapeutic Agents Receiving Food and Drug Administration Accelerated Approval. Milbank Q 2017;95:261-90. doi:10.1111/1468-0009.12261

92 Pease AM, Krumholz HM, Downing NS, Aminawung JA, Shah ND, Ross JS. Postapproval studies of drugs initially approved by the FDA on the basis of limited evidence: systematic review. BMJ 2017;357:j1680. doi:10.1136/bmj.j1680

93 Del Paggio JC, Azariah B, Sullivan R, et al. Do Contemporary Randomized Controlled Trials Meet ESMO Thresholds for Meaningful Clinical Benefit? Ann Oncol 2017;28:157-62. doi:10.1093/annonc/ mdw538

\section{Appendix: Supplementary material}

